\title{
The role of preoperative immune modulating nutrition
}

\author{
Bruce R. Bistrian \\ Department of Medicine, Harvard Medical School, Beth Israel Deaconess Medical Center, Boston, MA, USA \\ Correspondence to: Bruce R. Bistrian MD, PhD. Professor of Medicine, Harvard Medical School, Beth Israel Deaconess Medical Center, Boston, MA, \\ USA. Email: bbistria@bidmc.harvard.edu. \\ Provenance and Peer Review: This article was commissioned by the Editorial Office, Hepatobiliary Surgery and Nutrition. The article did not undergo \\ external peer review. \\ Comment on: Adiamah A, Skořepa P, Weimann A, et al. The Impact of Preoperative Immune Modulating Nutrition on Outcomes in Patients \\ Undergoing Surgery for Gastrointestinal Cancer: A Systematic Review and Meta-analysis. Ann Surg 2019;270:247-56.
}

Submitted Sep 23, 2019. Accepted for publication Sep 26, 2019.

doi: 10.21037/hbsn.2019.09.16

View this article at: http://dx.doi.org/10.21037/hbsn.2019.09.16

The meta-analysis by Adiamah et al. (1) clearly identifies the value of preoperative feeding with immune modulating nutrition(IMN) preoperatively in patients undergoing surgery for gastrointestinal cancer sufficient to make this a general recommendation by the relevant nutrition societies such as in future ESPEN and the Society of Critical Care Medicine-ASPEN guidelines $(2,3)$. Previously ESPEN has recommended IMN in malnourished patients following major cancer surgery $(2,4)$, but there has been some controversy as to whether IMN offered benefit beyond that seen with standard supplemental feeding in preoperative patients (5). However this present analysis appears to firmly establish the value of IMN in preoperative preparation of the gastrointestinal cancer patient undergoing surgery. That said there are significant and important characteristics of their analysis of 16 randomized trials of solely preoperative feeding in patients with gastrointestinal cancer that may have been critical in determining the significant outcomes of a marked reduction in infectious complications by nearly $1 / 2(\mathrm{OR}=0.52)$ with a $\mathrm{P}<0.0001$ and length of hospital stay by 1.57 days $(-2.48$ to -0.66$)$ with a $\mathrm{P}$ value $<0.0007$. Interestingly there was no impact on non-infectious complications, which might be anticipated, since enhancement of immune function would be expected to principally impact on the risk of infectious complications which could then secondarily influence length of stay. First the authors restricted the included studies to have only those patients with malignant disease with the preoperative feeding period to be at least 3 days, which included studies up to a total of 8 days duration. The former restriction tends to identify a group most likely to benefit from immune enhancement, and the latter trial condition reflects the minimal period necessary to effect a beneficial impact on immune function. The authors considered that the most likely to be effective component of this IMN would be the fish oil which requires at least 3 days for measurable incorporation into membrane phospholipids. A period of at least 3 days and ideally 7 days is similar to what was and still is thought to be necessary for preoperative total parenteral nutrition to have a significant clinical impact (6) related to repair of lean tissue including that for immune restoration. In 6 of the 16 studies cited there was an isonitrogenous, isocaloric control group whereas in the remaining 10 studies, the control group received only a standard diet. An isonitrogenous, isocaloric control supplement should improve the general nutritional status as well as the IMN would demonstrating the value of improved feeding per se in often malnourished patients. Although the infectious complications were significantly lower in both subgroups and overall, the secondary outcome, length of stay, was significantly shorter only in the total group and in those that did not receive supplemental nutrition, suggesting that there was a unique benefit of the IMN in terms of infectious complications with a less strong implication of the IMN for improvement in length of stay. To this point it is interesting that the authors note that one study that was just 3 days in duration and uniquely conducted in wellnourished patients with the other studies being 5-8 days long, there was no significant difference from controls, which is consistent with greater benefits to be anticipated in malnourished patients and with a sufficient period of nutritional rehabilitation. The important and defining characteristic of the present meta-analysis was their choice to study only one composition of IMN which also happens 
to be the one most widely studied. The original design of this IMN, which contained arginine, fish oil, nucleotides, and structured lipids initially and very early on in its commercial use the structured lipid was removed was that it was intended to work as a synergistic combination of immune-enhancing nutrients. The strongest evidence for the presumed effectiveness of this particular combination is for the ability of fish oil to have anti-inflammatory actions through its ability to alter production of pro-inflammatory eicosanoids like prostaglandin E2 and leukotriene B4 with less potent prostaglandins of the 3 -series and leukotrienes of the 5-series (7) combined with more recent evidence that eicosapentaenoic acid and docosahexaenoic acid also are the precursors for specialized pro-resolving mediators (SPMs) like maresins, resolvins, and neuroprotectins that actively terminate inflammation and promote healing (8). However arginine which can promote immune function in those with reduced immune function due to malnutrition and confer benefit might also enhance the systemic inflammatory response in others less malnourished and thereby might be potentially harmful which could in this circumstance be modulated by the presence of fish oilprovided eicosapentaenoic acid and docosahexaenoic acid (8). Thus it is important to have restricted the study to one IMN and not include other formulations of varied composition and amounts of immune-enhancing nutrients as has been done previously in some meta-analyses $(5,9)$.

In conclusion this very well defined and superbly conducted investigation has identified an important clinical advance that should lead to a wider use of IMN in the preoperative preparation of gastrointestinal cancer patients. The outcome is largely a consequence of the thought given to the study design, and the limited heterogeneity provides substantial confidence in the reported results.

\section{Acknowledgments}

Funding: None.

\section{Footnote}

Conflicts of Interest: The author has completed the ICMJE uniform disclosure form (available at https://hbsn.amegroups. com/article/view/10.21037/hbsn.2019.09.16/coif). The author has no conflicts of interest to declare.

Ethical Statement: The author is accountable for all aspects of the work in ensuring that questions related to the accuracy or integrity of any part of the work are appropriately investigated and resolved.
Open Access Statement: This is an Open Access article distributed in accordance with the Creative Commons Attribution-NonCommercial-NoDerivs 4.0 International License (CC BY-NC-ND 4.0), which permits the noncommercial replication and distribution of the article with the strict proviso that no changes or edits are made and the original work is properly cited (including links to both the formal publication through the relevant DOI and the license). See: https://creativecommons.org/licenses/by-nc-nd/4.0/.

\section{References}

1. Adiamah A, Skořepa $\mathrm{P}$, Weimann A, et al. The impact of preoperative immune modulating nutrition on outcomes in patients undergoing surgery for gastrointestinal cancer. A systematic review and meta-analysis. Ann Surg 2019;270:247-56.

2. Arends J, Bachmann P, Baracos V, et al. ESPEN guidelines on nutrition in cancer patients. Clin Nutr 2017;36:11-48.

3. McClave SA, Taylor BE, Martindale RG, et al. Guidelines for the provision and assessment of nutrition support therapy in the adult critically ill patient: Society of Critical Care Medicine (SCCM) and American Society for Parenteral and Enteral Nutrition (A.S.P.E.N.). JPEN J Parenter Enteral Nutr 2016;40:159-211.

4. Arends J, Baracos V, Bertz H, et al. ESPEN expert group recommendations for action against cancer-related malnutrition. Clin Nutr 2017;36:1187-96.

5. Hegazi RA, Hustead DS, Evans DC. Preoperative standard oral nutrition supplements vs immunonutrition: results of a systematic review and meta-analysis. J Am Coll Surg 2014;219:1078-87.

6. Veterans Affairs Total Parenteral Nutrition Cooperative Study Group. Perioperative total parenteral nutrition in surgical patients. N Engl J Med 1991;325:525-32.

7. Bistrian BR. Clinical aspects of essential fatty acid metabolism: Jonathan Rhoads Lecture. JPEN J Parenter Enteral Nutr 2003;27:168-75.

8. Serhan CN. Discovery of specialized pro-resolving mediators marks the dawn of resolution physiology and pharmacology. Mol Aspects Med 2017;58:1-11.

9. Probst P, Ohmann S, Klaiber U, et al. Meta-analysis of immunonutrition in major abdominal surgery. Br J Surg 2017;104:1594-608.

Cite this article as: Bistrian BR. The role of preoperative immune modulating nutrition. HepatoBiliary Surg Nutr 2020;9(2):221-222. doi: 10.21037/hbsn.2019.09.16 